\title{
Synthesis and Characterizations of Barium (Ba2+) and Strontium (Sr2+) Doped Bi0.9La0.1FeO3 System
}

Saleem Saleem ( $\nabla$ tabindat2014@gmail.com )

Devi Ahilya Vishwavidyalaya https://orcid.org/0000-0002-4361-4120

Nikita Karma

Govt (Model, Autonomous) Holkar Science College, Indore (M.P.) (452001)-India

Netram Kaurav

Govt (Model, Autonomous) Holkar Science College, Indore (M.P.) (452001)-India

H. S. Dagar

Govt (Model, Autonomous) Holkar Science College, Indore (M.P.) (452001)-India

\section{Research Article}

Keywords: structure, morphology, optical bandgap, dielectric properties

Posted Date: May 10th, 2021

DOI: https://doi.org/10.21203/rs.3.rs-498427/v1

License: (a) (i) This work is licensed under a Creative Commons Attribution 4.0 International License.

Read Full License 


\title{
Synthesis and Characterizations of Barium $\left(\mathrm{Ba}^{2+}\right)$ and Strontium $\left(\mathrm{Sr}^{2+}\right)$ Doped

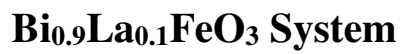

\author{
Nikita Karma $^{1}$, M. Saleem ${ }^{1,2 \#}$, Netram Kaurav ${ }^{1}$, H. S. Dagar ${ }^{1}$ \\ ${ }^{1}$ Govt (Model, Autonomous) Holkar Science College, Indore (M.P.) (452001)-India \\ ${ }^{2}$ School of Physics, Vigyan Bhavan, Devi Ahilya University, Khandwa Road Campus, Indore \\ 452001, India
}

\begin{abstract}
We discuss synthesis and various characterizations of $\mathrm{Bi}_{0.9} \mathrm{La}_{0.1-x}(\mathrm{Ba} / \mathrm{Sr})_{\times} \mathrm{FeO}_{3}[x$ $=0,0.05]$ ceramics. We synthesized these ceramics by solid state reaction method and the samples so synthesized were characterized for structural elucidation exploiting X-ray diffraction technique. The XRD data on Rietveld refinement inferred that all the prepared samples have acquired monoclinic phase with space group CI. Morphology of the samples revealed highly grown grains with moderate grain boundary development carried out exploiting field emission scanning electron microscopy (FESEM) technique. The Energy dispersive analysis of X-ray diffraction (EDAX) spectra analysis confirmed that composition is retained with absence of any foreign impurity. UVVis spectral studies of these ceramics confirmed that optical bandgap value about $2.2 \mathrm{eV}$ highly recommended in photocatalytic and opto-electronic device applications. Room temperature dielectric studies revealed that samples are extremely good dielectric materials retained even after $1 \mathrm{MHz}$ applied field. The main feature is the dielectric loss which is negotiable for their capability in the modern device applications. Impedance analysis reveals the samples exhibit distributed relaxation times and inherit non-Debye behavior revealed from the depressed semicircles whose centers does not lie on $\mathrm{x}$-axis.
\end{abstract}

Keywords: structure; morphology; optical bandgap; dielectric properties.

Author for Correspondence: M. Saleem (tabindat2014@gmai.com) 


\section{Introduction}

Multiferroic materials are center of interest of materials researchers as they can be modified for their magnetic properties using electric field and vice versa. Materials with such properties have potential applications in conversion of electromagnetic energy, sensors based on magnetoelectric (ME) effect, magnetic memories and much more. However to exploit these materials, we require room temperature magneto-electrical coupling, stable structures at micro levels, and recognizable magnetic characteristics which include good remnant magnetization, low coercive field or reduced dc-leakage currents [1-3].

Bismuth ferrite $\left(\mathrm{BiFeO}_{3}\right)$ is considered to be the good multiferroic material however lower room temperature magnetic properties limited its applications. There are few hindrances in the way of $\mathrm{BiFeO}_{3}$ in the bulk form to suit in device applications such as difficulty to synthesize pure BFO due to instability of its perovskite phase above $948 \mathrm{~K}$ [4]. Also there exists high dielectric loss and conductivity problems arising from the mixed valence states of $\mathrm{Fe}$ ion viz. $\mathrm{Fe}^{2+} / \mathrm{Fe}^{3+}$ and vacancies related to oxygen thereby hinders its ferroelectric properties. Additionally, the presence of spiral spin modulation, we are refrained to achieve ferromagnetism with definite magnetization in BFO system [5]. BFO is a typical ferroelectric material [6] with band gap about $2.2 \mathrm{eV}$. In addition, its nontoxicity, stability, and low cost enhances its potential as photoelectrocatalytic water oxidation. It is worth to mention here that optical properties of BFO highly rely on shape and size of BFO crystals [7].

The Curie temperature and Neel temperature of $\mathrm{BiFeO}_{3}$ is $\mathrm{T}_{\mathrm{C}} \sim 1103 \mathrm{~K}$ ) and $\mathrm{T}_{\mathrm{N}} \sim 643 \mathrm{~K}$ respectively making it a unique materials [8]. $\mathrm{BiFeO}_{3}$ exhibits low values of polarization and magnetization attributed to problems related to leakage current and overlapping between spin spiral structure and order of G-type antiferromagnetic if taken seriously brighten its future in device applications [9].

To improve the properties of $\mathrm{BiFeO}_{3}$, researchers have found that substitution of $\mathrm{Bi}$ site or Fe site by metal ions is effective way. Substitution at A-site of BFO [10] leads to the variation of lattice structure, spin spiral structure is suppression and stoichiometry is enhanced thereby oxygen vacancies are eliminated which leads to the effectiveness of $\mathrm{BiFeO}_{3}$ system [11]. 
Usually Bi-site is substituted by rare earth metals. As these metals exhibit non-filled forbitals, they possess plausible magnetic moment and couple magnetically with $\mathrm{Fe}^{3+}$ ions due to active $4 \mathrm{f} \mathrm{electrons.} \mathrm{As} \mathrm{a} \mathrm{result,} \mathrm{their} \mathrm{substitution} \mathrm{is} \mathrm{expected} \mathrm{to} \mathrm{improve} \mathrm{magnetization} \mathrm{values} \mathrm{[12].}$ In addition, there are reports [13-15] that has attracted the interest. These reports reveal interesting results when Bi site in BFO system is substituted by alkaline earth $\mathrm{Sr}^{2+}$ metal ions which is nonmagnetic in nature allowing its substitution due to its nearly equal ionic radius to that of $\mathrm{Bi}^{3+}$ ions. These studies reveal decrease in dielectric constant with the substitution of ion with higher ionic radii ( $\mathrm{Ba}, \mathrm{Sr}, \mathrm{Ca}$ ) $\mathrm{BiFeO}_{3}$ system [14]. Substitution of $\mathrm{Bi}$-site by $\mathrm{Sr}^{2+}$ ions is observed to enhance magnetization value $\mathrm{BiFeO}_{3}$ system as it results in the charge disturbance thereby spiral spin structure is suppressed [15]. Furthermore, particle size is also expected to affect magnetic, electric and ferroelectric nature of substituted BFO system [16, 17].

In the current study, we report $\mathrm{Bi}_{0.9} \mathrm{La}_{0.1-\mathrm{x}}(\mathrm{Ba} / \mathrm{Sr})_{\mathrm{x}} \mathrm{FeO}_{3}[x=0,0.05]$ ceramics synthesized by solid state reaction route. We hereby emphasized on the structural, optical and electric nature of these perovskite materials. The effect of magnetic rare-earth and non-magnetic alkaline earth metal ions at Bi-site of $\mathrm{BFO}$ is provided in detail.

\section{Synthesis}

To prepare $\mathrm{Bi}_{0.9} \mathrm{Laa}_{0.1-\mathrm{x}}(\mathrm{Ba} / \mathrm{Sr})_{\mathrm{x}} \mathrm{FeO}_{3}[x=0,0.05]$ ceramics materials, we used solid-state reaction technique. The starting materials used were Bismuth Oxide $\left(\mathrm{Bi}_{2} \mathrm{O}_{3}\right)$, Strontium carbonate $\left(\mathrm{SrCO}_{3}\right)$, Iron Oxide $\left(\mathrm{Fe}_{2} \mathrm{O}_{3}\right)$, Barium carbonate $\left(\mathrm{BaCO}_{3}\right)$ and Lanthanum Oxide $\left(\mathrm{La}_{2} \mathrm{O}_{3}\right)$ powders. These powers were mixed in stoichiometric ratio through mechanical grinding 4 hours using ethanol for proper dispersion of precursors and the mixture was calcined for 5 hours at $650^{\circ} \mathrm{C}$ and at $800^{\circ} \mathrm{C}$ for 5 hours after regrinding it for $3 \mathrm{~h}$ again. The process used is also called the double calcination process [18]. The double calcined mixture is powdered and mixed with PVA (Polyvinlyalcohol) as binder. The material is then pressed into pellets with dimensions of diameter $10 \mathrm{~mm}$ and $1 \mathrm{~mm}$ thickness under pressure of 2.5 ton. The pellets so prepared were sintered at $850^{\circ} \mathrm{C}$ for $4 \mathrm{~h}$ finally.

\section{Characterization}

For the confirmation of structure acquired by the synthesized samples, the XRD spectrum was obtained by $\mathrm{x}$-ray diffractometer with $\mathrm{Cu}-\mathrm{K} \alpha 1$ radiation of wavelength $\lambda=1.5406 \AA$ at room temperature. For verification of compositional, the EDAX spectra was obtained using the energydispersive spectrometer, model EDS Oxford Instrument INCA, X-sight7557. Field emission 
scanning electron micrograph (FESEM) images were taken to emphasize on morphology, using FESEM instrument model JEOLJSM-6500F. The dielectric measurements on the synthesized samples was done on the instrument of Model E4980A Precision LCR meter (2 Hz-2 MHz) from Keysight Technologies. Perkin Elmer, Lambda 950-USA made UV-Vis spectrometer was used for optical band gap determination.

\section{X-ray Diffraction Analysis}

The effect $\mathrm{La}^{3+}, \mathrm{Ba}^{2+}$ and $\mathrm{Sr}^{2+}$ on crystal structure and phase formation of $\mathrm{BFO}$ is investigated by using X-ray Diffraction technique. The identical XRD pattern of $\mathrm{Bi}_{0.9} \mathrm{La}_{0.1} \mathrm{FeO}_{3}$ (BLFO), $\mathrm{Bi}_{0.9} \mathrm{La}_{0.1}$ ${ }_{x} \mathrm{Ba}_{0.05} \mathrm{FeO}_{3}[\mathrm{BLBFO}]$ and $\mathrm{Bi}_{0.9} \mathrm{Laa}_{0.1-x} \mathrm{Sr}_{0.05} \mathrm{FeO}_{3}$ [BLSFO] ceramics on investigation infers that all samples possess monoclinic structure with C1c1 space group [18.19]. It has been revealed from the analysis of XRD spectra of the as synthesized materials that all samples exhibit single-phase characteristics but the peak in BLBFO at $29.55^{\circ}$ shows the formation of minor secondary phases due to $\mathrm{BaCO}_{3}$ which is highlighted by star (*) mark in Figure1. The XRD patterns of BLBFO and BLSFO display splitting of the diffraction peaks at $32^{\circ}, 39.5^{\circ}, 57^{\circ}$ which is attributed to the temperature effect.

The identical peaks in the as synthesized ceramic witness the effective replacement of $\mathrm{Bi}^{3+}$ site by $\mathrm{La}^{3+}, \mathrm{Sr}^{2+}$ and $\mathrm{Ba}^{2+}$ ions possibly due to the nearly equal ionic radii of the A-Site host and guest ions. The highly intense and sharp diffraction peaks infer higher crystallinity acquired by the ceramics under observation and lower FWHM of the diffraction peaks is indicative of higher average crystallite size calculated from the characteristic XRD peaks via Debye Scherrer's Equation, $D=K \lambda / \beta \cos \theta$, where $\mathrm{K}($ a constant $)=0.9, \beta($ in radian $)=$ full width at half maxima and $\theta=$ Bragg angle of the reflection peaks. The computed average crystallite size of BLFO, BLBFO and BLSFO ceramics were found to be $47.39 \mathrm{~nm}, 34.32 \mathrm{~nm}$ and $31.20 \mathrm{~nm}$ respectively.

The verification of results of XRD data was carried out Rietveld Refinement of XRD spectra using the Fullprof software as Figure 1 reveals. The value of different parameters related

to crystal structure such as Space group, Volume, Density, etc. obtained from the Rietveld Refinement are documented in Table 1. The 3-D crystal structure developed by VESTA software for BLFO ceramic is shown as Figure 2. 
In addition, Williamson-Hall (W-H) approach was exploited to get insight of induced strain in the structure affected due to higher temperature treatment and varied ionic radii and dopants. Furthermore, W-H study helps to calculate particle size more accurately in a new fashion. Figure 3 presents $\mathrm{W}-\mathrm{H}$ plot for all the $\mathrm{Bi}_{0 .} \mathrm{La}_{0.1-\mathrm{x}}(\mathrm{Ba} / \mathrm{Sr})_{\mathrm{x}} \mathrm{FeO}_{3}[x=0,0.05]$ ceramics under observation. The particle size obtained are $78.8 \mathrm{~nm}, 61.96 \mathrm{~nm}$ and $61.6 \mathrm{~nm}$ whereas induced strain calculated from the $\mathrm{W}-\mathrm{H}$ plot is $1.8 * 10^{-3}, 2.84 * 10^{-3}$ and $3.18^{*} 10^{-3}$ for BLFO, BLBFO and BLSFO respectively.

\section{Compositional and Microstructural studies}

The $\mathrm{Bi}_{0.9} \mathrm{La}_{0.1-\mathrm{x}}(\mathrm{Ba} / \mathrm{Sr})_{\mathrm{x}} \mathrm{FeO}_{3}[x=0,0.05]$ ceramic materials were investigated for compositional studies employing energy dispersive analysis of X-ray (EDAX) technique. From Figure 4 which presents EDAX spectra of the as synthesized samples on analysis revealed that the composition is retained. The integral elements of the samples are found to be present and there is no foreign impurity within the limits of experiment. Further the presence of concentration is well revealed from the intenseness of the corresponding elements. It opens the way for emphasizing the impact of various substitutions in $\mathrm{n}$ the matrix of $\mathrm{BFO}$ on its structural, optical and electrical properties.

Associated to EDAX, the compositional characterization, morphology that highly impacts the physical properties of the material is indispensable to be understood. For this, we dis field emission scanning electron microscopic characterization (FE-SEM) and images thus obtained are displayed as the insets of their respective EDAX spectra in Figure 4. From close look. The FESEM images show highly grown grains due to high temperature firing during sintering process. Despite well-developed grains, we witness moderate developed grain boundaries which are sharp in case of BLFO and become loose for SR and Ba doped BLFO system. We further observe the empty sites in the FESEM images which may affect the dielectric and ferroelectric properties. We calculated average grain size exploiting the scale given the images and found it to be $1.2 \mu \mathrm{m}$, $0.45 \mu \mathrm{m}$ and $0.97 \mu \mathrm{m}$ for BLFO, BLBFO and BLSFO respectively.

\section{Optical Bandgap Studies}

For opto-electronic device applications, we subjected $\mathrm{Bi}_{0.9} \mathrm{La}_{0.1-\mathrm{x}}(\mathrm{Ba} / \mathrm{Sr})_{\mathrm{x}} \mathrm{FeO}_{3}[x=0,0.05]$ ceramic materials to the UV-Vis radiations and recorded diffuse reflectance spectra in the wavelength range of $250 \mathrm{~nm}-860 \mathrm{~nm}$. The equation $\alpha \mathrm{hv}=\mathrm{A}(\mathrm{hv}-\mathrm{Eg})^{\mathrm{n}}$ [20] is exploited to estimate the bandgap of these materials; where $\alpha$ is absorption coefficient, $\mathrm{h}$ is Planck constant, $v$ is light frequency, A is 
proportionality constant, and $E_{\mathrm{g}}$ represent band gap respectively. The power $\mathrm{n}=2,0.5$ presents direct and indirect transition. Literature reveals that BFO is direct band gap material i.e. $\mathrm{n}=2$ [21]. The DRS data was arranged according to Kubelka-Munk function and plotted $[\mathrm{F}(\mathrm{R}) \mathrm{h} v]^{2}$ as a function of E (hv) known as Tauc's plot displayed as Figure 5. The estimated band gap value rounds about $2 \mathrm{eV}$, obtained from the intersection of extrapolated lines along the sharp edge and line through data nearly parallel to the energy axis along the energy independent data which agrees with the report [22]. The comparatively lower band gap of the as synthesized BFO based ceramics is expected to enhance the absorption of visible light thereby improve photoelectrocatalytic activities

\section{Dielectric studies}

A significant role is played by dipolar and interfacial polarization in the dielectric behavior of $\mathrm{BiFeO}_{3}$ materials at lower frequencies whereas higher frequencies regions are dominated by electronic and ionic polarizations [23]. Figure 6 illustrates room temperature dielectric constant as a function of log of frequency of BLFO, BLBFO and BLSFO ceramics. The dielectric constant in the low-frequency region is comparatively high, which declines slowly with the increase in frequency and displays frequency independence in the higher frequency regions. The higher dielectric constant in low region of frequency arise from the accumulation of charge at the grain boundaries. In the high-frequency region, dipoles disobey the applied electric field thereby confirms the polar characteristics for all the samples [24, 25]. Since dielectric medium comprises of low conducting grain boundaries and good conducting grains which gives rise to a space charge polarization in the low frequency region. It is attributed to the structural heterogeneity of the sample resulting in the enhanced dielectric permittivity values.

The dispersion is witnessed from the decreasing trend in the values of dielectric constant with increasing frequency explainable in terms of Maxwell-Wagner model [26, 27], and thereby agrees with the Koop's phenomenological theory. These space charges are believed to exist due to vacancies corresponding to bismuth and oxygen and responds to the applied ac field in the region of low frequency and thus contributes to the dielectric constant where $\mathrm{Bi}\left(V_{B i}^{3-}\right)$ volatility leads to oxygen vacancies $\left(V_{O}^{2+}\right)$. However they do not respond to the ac field and undergo relaxation in the region of higher frequency. Electron hopping at $\mathrm{FeO}_{6}$ octahedra sites between $\mathrm{Fe}^{2+}$ and $\mathrm{Fe}^{3+}$ ions leads to the dispersion of dielectric constant. The higher dielectric constant in 
BLBFO may result from the replacement of $\mathrm{Bi}^{3+}$ by $\mathrm{Ba}^{2+}$ by inducing a higher density of vacancies thereby enhances conduction by hopping mechanism.

Figure 7 displays dielectric loss of BLFO, BLBFO and BLSFO ceramics as a function of $\log$ of frequency. The dielectric loss data follows the same trend as for the dielectric constant for BLBFO and BLSFO samples except BLFO. In the low-frequency region, the resistivity increases as dielectric loss is greater due to the accumulation of charges. Substitution of $\mathrm{Ba}^{2+}$ and $\mathrm{Sr}^{2+}$ is expected to increase the oxygen vacancies which enhance conduction mechanism via hopping thereby exhibit higher dielectric loss as compared to BLFO.

Figure 8 shows the variation of conductivity, $\sigma_{\mathrm{ac}}$ as a function of logarithm of frequency. The low frequency region in the conductivity curves shows dispersion. Initially, conductivity, $\sigma_{a c}$ is irresponsive to the applied field upto a certain limit and after that limit it becomes sensitive in the region of higher frequency. However, cationic disorder among neighboring sites, and the presence of space charge results in the increase of $\sigma_{\mathrm{ac}}$ with rise in frequency.

Figure 9 depicts $Z^{\prime \prime}$ vs. $Z$ plots usually called the Cole-Cole plot. The curves of all the samples exhibit semicircular nature. However, a small shift in the center of all the arcs from the real axis $Z^{\prime}$ is observed attributed to the non-Debye type relaxation. This further infers the distribution of relaxation time around the mean relaxation time given by $\tau_{m}=1 / \omega_{m}$. This discrepancy arise from a number of ways where strain, distribution of grain size, stress to grain boundary, and volume fraction of the comprising elements play the crucial role. We have tried to explain the microstructure of the doped $\mathrm{BiFeO}_{3}$ using the Cole-Cole plots. The appearance of single semicircle indicates that electrodes and contacts contribute negligible impedance [28, 29]. The impedance data was fitted using Zview software and the circuits that fit the given impedance data are displayed as Figure 9(a) and (b).

To explore electrical properties of a material, study of Complex modulus stands as alternative approach and is useful to get insight of any other effects exhibited by the sample. The dynamical aspects of phenomena of electrical transport, there determination, analysis and interpretation which include parameters viz. rate of carrier/ion hopping, relaxation time, etc. are understood using this important and convenient tool. For all doped $\mathrm{BiFeO}_{3}$ ceramics, the complex electric modulus spectrum M' versus M", the Nyquist plot is shown in Figure 10. The presence of little asymmetric and depressed semicircular arcs characterize the $\mathrm{M}^{\prime}$ versus $\mathrm{M}^{\prime \prime}$ patterns. It is 
observed that the centers of these depressed semicircles does not lie on $\mathrm{M}^{\prime}$ axis. The behavior of Nyquist plot electric is indicative of hopping type of mechanism responsible for electric conduction and non-Debye type dielectric relaxation exhibited by the doped BFO systems under observation $[30,31]$.

\section{Polarization Studies}

We investigated $\mathrm{Bi}_{0.9} \mathrm{La}_{0.1-\mathrm{x}}(\mathrm{Ba} / \mathrm{Sr})_{\mathrm{x}} \mathrm{FeO}_{3}[x=0,0.05]$ ceramic materials for ferroelectric properties. Figure 11 represents $\mathrm{P}-\mathrm{E}$ loop for these ceramic materials plotted as a response of induced polarization when electric field is applied. From the plots, it is evident that the samples under observation exhibit weak polarization. The large structural inhomogeneities and lattice distortions induced by alkaline earth metals has affected the polarization when compared to rare earth $\mathrm{La}^{3+}$ doped BFO system. P- E loop displayed by BLFO system though good compared with other competents here still display lossy character, absence of sharp saturation and large coercive field. The case is enhanced on doping BLFO system by $\mathrm{Ba}^{2+}$ and $\mathrm{Sr}^{2+}$ ions $[32,33]$. This is expected to arise from the conducting nature of the samples as BFO systems are reported so. As discussed above, the doping of alkaline earth metal ions at Bi-site is likely to enhance dielectric nature of the samples under study but excessive distortions and inhomogeneties have been disrupted though polarization axis show higher values compared to BLFO system.

\section{Conclusion}

We successfully synthesized $\mathrm{Bi}_{0 .}{ }_{9} \mathrm{La}_{0.1-\mathrm{x}}(\mathrm{Ba} / \mathrm{Sr})_{\mathrm{x}} \mathrm{FeO}_{3}[x=0,0.05]$ samples by solid state reaction route. Rietveld refinement of XRD data revealed that all the synthesized samples have acquired monoclinic crystal structure. The well-developed grain boundary has been found to contribute to dielectric properties. The lower optical bandgap of these materials suit for photocatalytic activities. The higher dielectric constant and lower loss value witness their usefulness in device applications. Impedance analysis reveal the samples exhibit non-Debye character and exhibit distributed relaxation times. P-E loop study inferred the samples are lossy in and exhibit conducting nature.

\section{Acknowledgments}

UGC-DAE-CSR-Indore (M.P.)-India is acknowledged as an Institute for providing characterization facilities. Heart-felt thanks are extended to Dr. M. Gupta, Dr. U. Deshpande, Dr. 
V. Reddy, Dr. R. Rawat for timely characterization and guidance. Dr. Rupesh Dewan, IIT Indore is gratefully acknowledged for FESEM/EDAX characterization.

\section{References}

[1] M. Y. Shami, S. Awan, M. Anis-Ur-Rehman, J. Alloys. Comp. 509 (2011) 10139- 10144.

[2] S. Chauhan, M. Kumara, S. Chhoker, S.C. Katyal, H. Singh, M. Jewariya, K.L. Yadav, Solid State Commun. 152 (2012) 525-529.

[3] R. K. Mishra, D. K. Pradhan, R. N. P. Choudhary, A. Banerjee, J. Phys.: Condens. Matter 20 (2008)

[4] Y. P. Wang, L. Zhou, M. F. Zhang, et al., Appl. Phys. Lett. 84 (2004) 1731-1733.

[5] T. J. Park, G.C. Papaefthymiou, A.J. Viescas, et al., Nano. Lett. 7 (2007) 766-772.

[6] X. Y. Zhang, C. W. Lai, X. Zhao, D. Y. Wang, J. Y. Dai Appl Phys Lett 87 (2005) 143102

[7] X. Xu, Lin YH, Li P, Shu L, Nan CW J Am Ceram Soc 94 (2011) 2296-2299

[8] C. J. Tsai, C. Y. Yang, Y. C. Liao, Y. L. Chueh J Mater Chem 22 (2012) 17432-17436.

[9] T. J. Park, G. C. Papaefthymiou, A. J. Viescas, A.R. Moodenbaugh, S.S. Wong, Nano Lett. 7 (2007) 766.

[10] G. L. Song, J. Su, G. J. Ma, T. X. Wang, H. G. Yang, F. G. Chang, Mater. Sci. Semicond. Proc. 27 (2014) 899.

[11] F. Yan, M.O. Lai, Li Lu, J. Phys. D. Appl. Phys. 45 (2012), 325001.

[12] R. Guo, L. Fang, W. Dong, F. Zheng, M. Shen, J. Phys. Chem. C 114 (2010) 21390.

[13] S. K. Mandal, T. Rakshit, S. K. Ray, S. K. Mishra, P. S. R. Krishna, A. Chandra, J. Phys. Condens. Matter 25 (2013), 055303.

[14] B. Bhushan, A. Basumallic, S. K. Bandopadhyay, N. Y. Vasanthacharya, D. Das, J. Phys. D. Appl. Phys. 42 (2009) 065004.

[15] B. Wang, S. Wang, L. Gong, Z. Zhou, Ceram. Int. 38 (2012) 6643. 
[16] A. Jaiswal, R. Das, T. Maity, K. Vivekanand, S. Adyanthaya, J. Phys. Chem. C. 114 (2010) 12432-12439.

[17] J. Z. Huang, Y. Wang, Y. Lin, M. Li, C.W. Nan, J. Appl. Phys. 106 (2009), 063911.

[18] D. Rout, K. S. Moon and S. J. L. Kang, Raman Spectrosc., 40 (2009) 618-626

[19] R. Palai, H. Schmid, J. F. Scott, and R. S. Katiyar, Physical Review B 81 (2010) 064110

[20] Y. C. Yang, Y. Liu, J. H. Wei, C. X. Pan, R. Xiong, J. Shi, RSC Adv 4 (2014) 3194131947

[21] S. T. Zhang, Y. Zhang, M. H. Lu, C. L. Du, Y. F. Chen, Z. G. Liu, Y. Y. Zhu, N. B. Ming Appl. Phys. Lett. 88 (2006) 162901

[22] U. A. Joshi, J. S. Jang, P. H. Borse, J. S. Lee, Appl Phys Lett 92 (2008) 242106-242106-3

[23] D. Guan, Z. Gao, W. Yang, J. Wang, Y. Yuan, B. Wang, M. Zhang, L. Liu, Mater. Sci. Eng. B 178 (2013) 736-743.

[24] G. Dhir, P. Uniyal, N. K. Verma, Physica B: Condensed Matter, 531 (2018) 51

[25] G. Dhir, G. S. Lotey, P. Uniyal, N. K. Verma, J. Mater Sci. Mater Electron 24 (2013) 4386

[26] J. C. Maxwell, Electricity and Magnetism (Oxford University Press, Oxford, England, 1 (1929) Sec. 328.

[27] K. W. Wagner, Ann. Phys. 40 (1913) 817

[28] J. Khajonrit, U. Wongpratat, P. Kidkhunthod, S. Pinitsoontorn, S. Maensiri, Journal of Magnetism and Magnetic Materials 449 (2018) 423-434.

[29] M. Saleem, S. Tiwari, M. Soni, N. Bajpai and A. Mishra, International Journal of Modern Physics B, 34 (2020) 2050033.

[30] W. Yang, Z. Gao, J. Wang, B. Wang, Q. Liu, Z. Li, T. Mann, P. Yang, M. Zhang, L. Liu, Electrochim. Acta 69 (2012) 112-119

[31] L. M. S. Medina, G. A. Jorge, R. M. Negr, J. Alloys. Comp. 592 (2014) 306

[32] Y. Tiana, F. Xuec, Q. Fua, L. Zhoua, C. Wanga, H. Goua, M. Zhanga (2017), Ceramics International, doi.org/10.1016/j.ceramint.2017.12.013. 
[33] N. Wang, X. Luo, L. Han, Z. Zhang, H. Olin, Y. Yang, Nano-Micro Lett. 12 (2020) 81

\section{Figure Captions}

Figure 1: Rietveld Refinement of X-ray diffraction data of $\mathrm{Bi}_{0.9} \mathrm{La}_{0.1-\mathrm{x}}(\mathrm{Ba} / \mathrm{Sr})_{\mathrm{X}} \mathrm{FeO}_{3}[x=0,0.05]$ ceramic materials

Figure 2: 3-D monoclinic crystal structure acquired by $\mathrm{Bi}_{0.9} \mathrm{La}_{0.1} \mathrm{FeO}_{3}$ sample

Figure 3: Williamson-Hall plot of $\mathrm{Bi}_{0.9} \mathrm{La}_{0.1-\mathrm{x}}(\mathrm{Ba} / \mathrm{Sr})_{\mathrm{x}} \mathrm{FeO}_{3}[x=0,0.05]$ ceramic materials

Figure 4: EDAX spectra and FESEM images (inset) of $\mathrm{Bi}_{0.9} \mathrm{La}_{0.1-\mathrm{x}}(\mathrm{Ba} / \mathrm{Sr})_{\mathrm{x}} \mathrm{FeO}_{3}[x=0,0.05]$ ceramic materials

Figure 5: Tuac's plots for the estimation of optical bandgap of $\mathrm{Bi}_{0.9} \mathrm{Laa}_{0.1-\mathrm{x}}(\mathrm{Ba} / \mathrm{Sr})_{\mathrm{x}} \mathrm{FeO}_{3}[x=0,0.05]$ ceramic materials

Figure 6; Dielectric constant of $\mathrm{Bi}_{0 .}{ }_{9} \mathrm{La}_{0.1-\mathrm{x}}(\mathrm{Ba} / \mathrm{Sr})_{\mathrm{x}} \mathrm{FeO}_{3}[x=0,0.05]$ ceramic materials

Figure 7: Dielectric loss $(\tan \delta)$ for $\mathrm{Bi}_{0.9} \mathrm{La}_{0.1-\mathrm{x}}(\mathrm{Ba} / \mathrm{Sr})_{\mathrm{x}} \mathrm{FeO}_{3}[x=0,0.05]$ ceramic materials

Figure 8: ac conductivity of $\mathrm{Bi}_{0.9} \mathrm{La}_{0.1-\mathrm{x}}(\mathrm{Ba} / \mathrm{Sr})_{\mathrm{x}} \mathrm{FeO}_{3}[x=0,0.05]$ ceramic materials

Figure 9: Nyquist plot of $\mathrm{Bi}_{0.9} \mathrm{La}_{0.1-\mathrm{x}}(\mathrm{Ba} / \mathrm{Sr})_{\mathrm{x}} \mathrm{FeO}_{3}[x=0,0.05]$ ceramic materials

Figure 9 (a) and (b): (a) ciruit for BLFO and (b) Circuit for BLBFO and BLSFO

Figure 10: Cole-Cole plot for $\mathrm{Bi}_{0.9} \mathrm{La}_{0.1-\mathrm{x}}(\mathrm{Ba} / \mathrm{Sr})_{\mathrm{x}} \mathrm{FeO}_{3}[x=0,0.05]$ ceramic materials

Figure 11; Polarization (P-E) loops of $\mathrm{Bi}_{0.9} \mathrm{La}_{0.1-\mathrm{x}}(\mathrm{Ba} / \mathrm{Sr})_{\mathrm{x}} \mathrm{FeO}_{3}[x=0,0.05]$ ceramic materials 
Figures
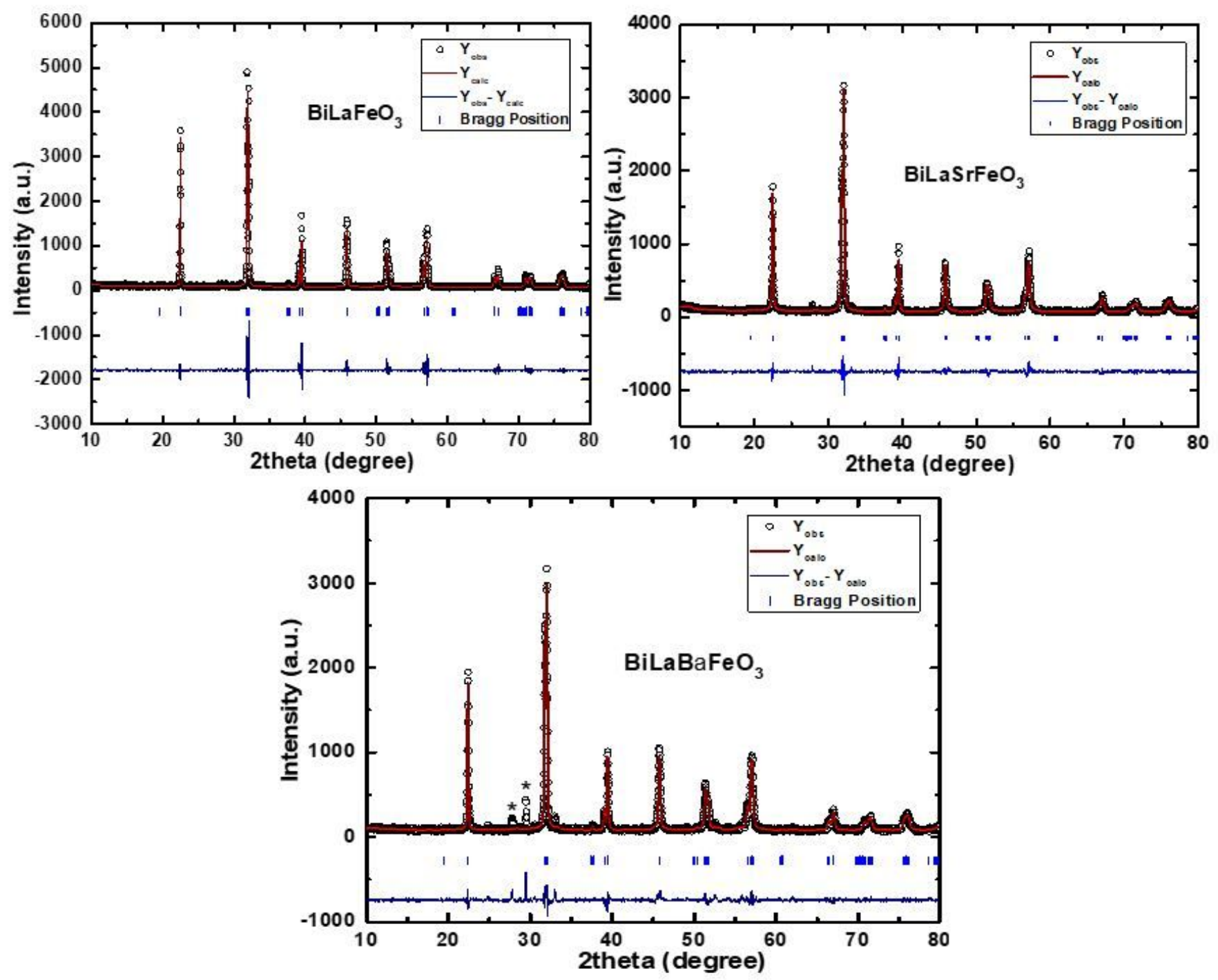

Figure 1

Rietveld Refinement of X-ray diffraction data of Bi0.9La0.1-x(Ba/Sr)xFeO3 $[x=0,0.05]$ ceramic materials 


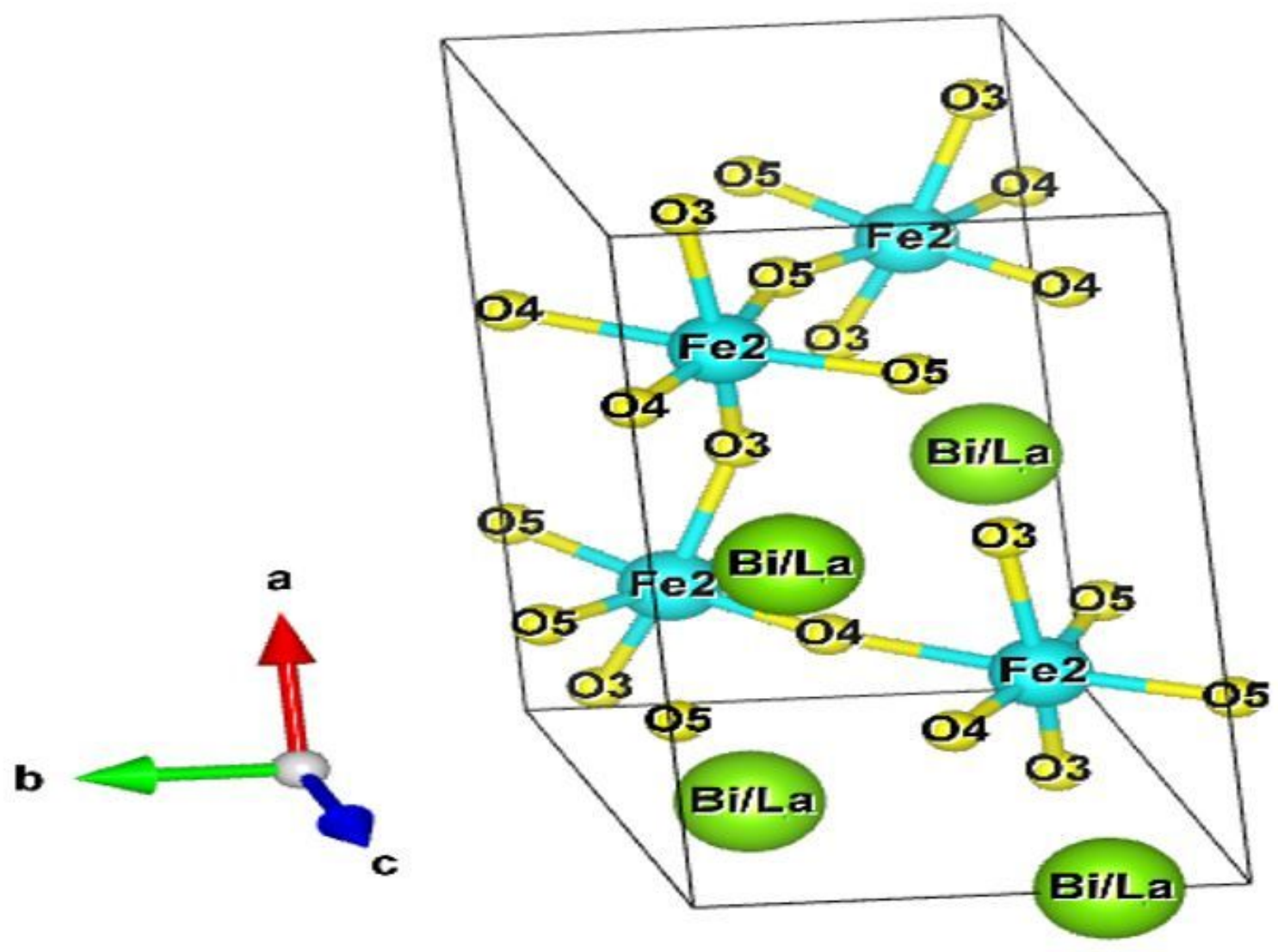

Figure 2

3-D monoclinic crystal structure acquired by Bi0.9La0.1FeO3 sample 


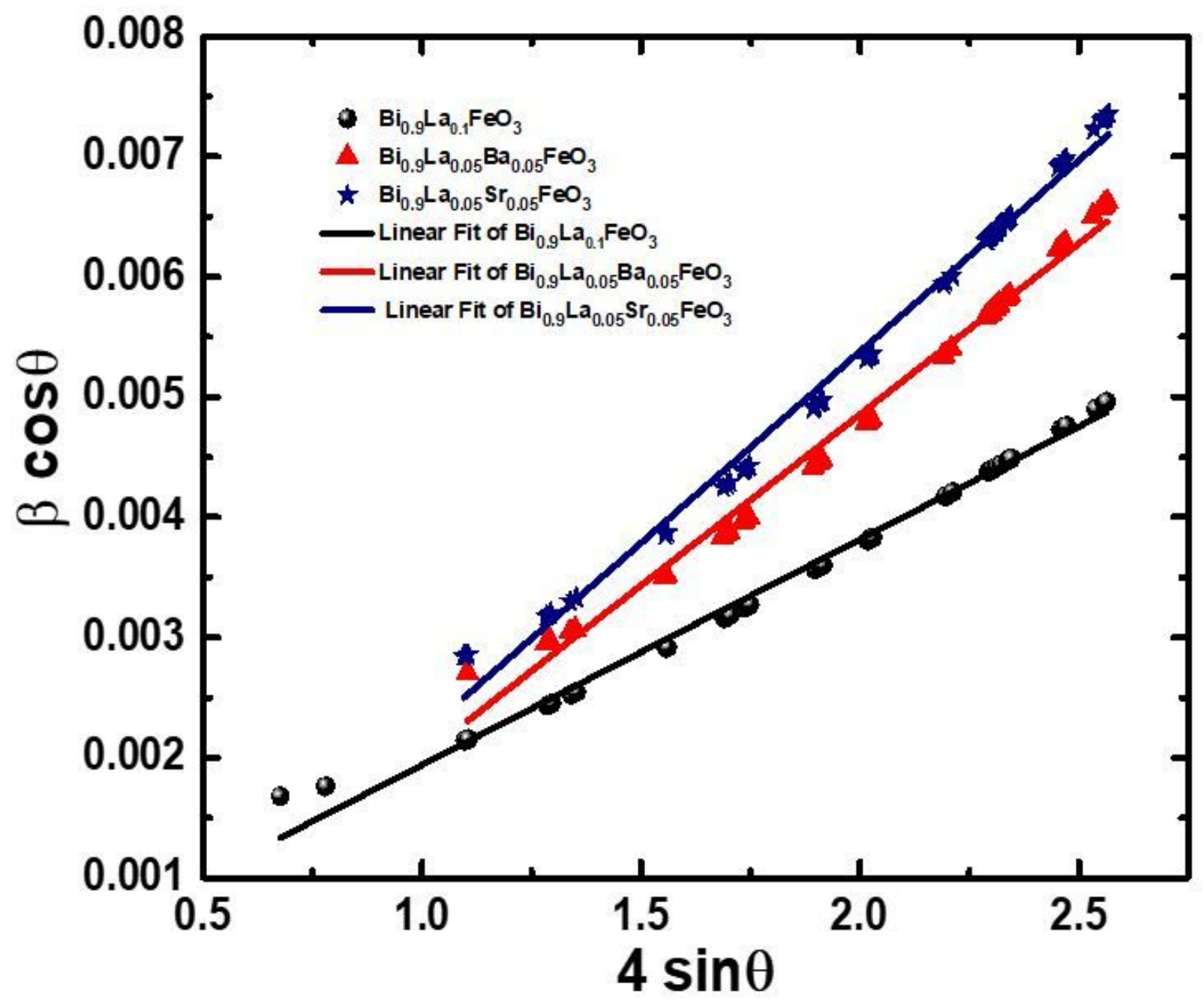

Figure 3

Williamson-Hall plot of Bi0.9La0.1-x(Ba/Sr)xFeO3 $[x=0,0.05]$ ceramic materials 

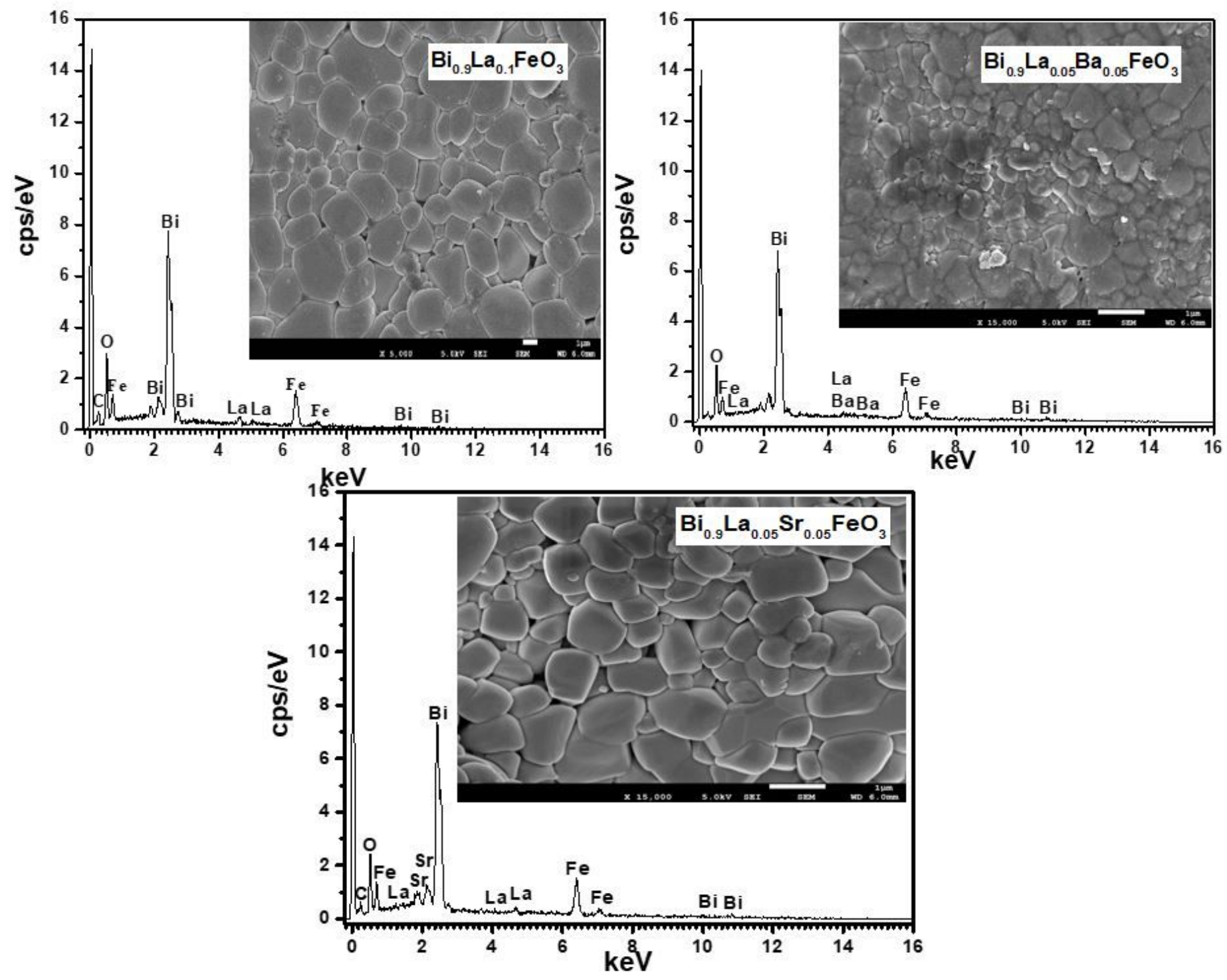

Figure 4

EDAX spectra and FESEM images (inset) of Bi0.9La0.1-x(Ba/Sr)xFeO3 $[x=0,0.05]$ ceramic materials 


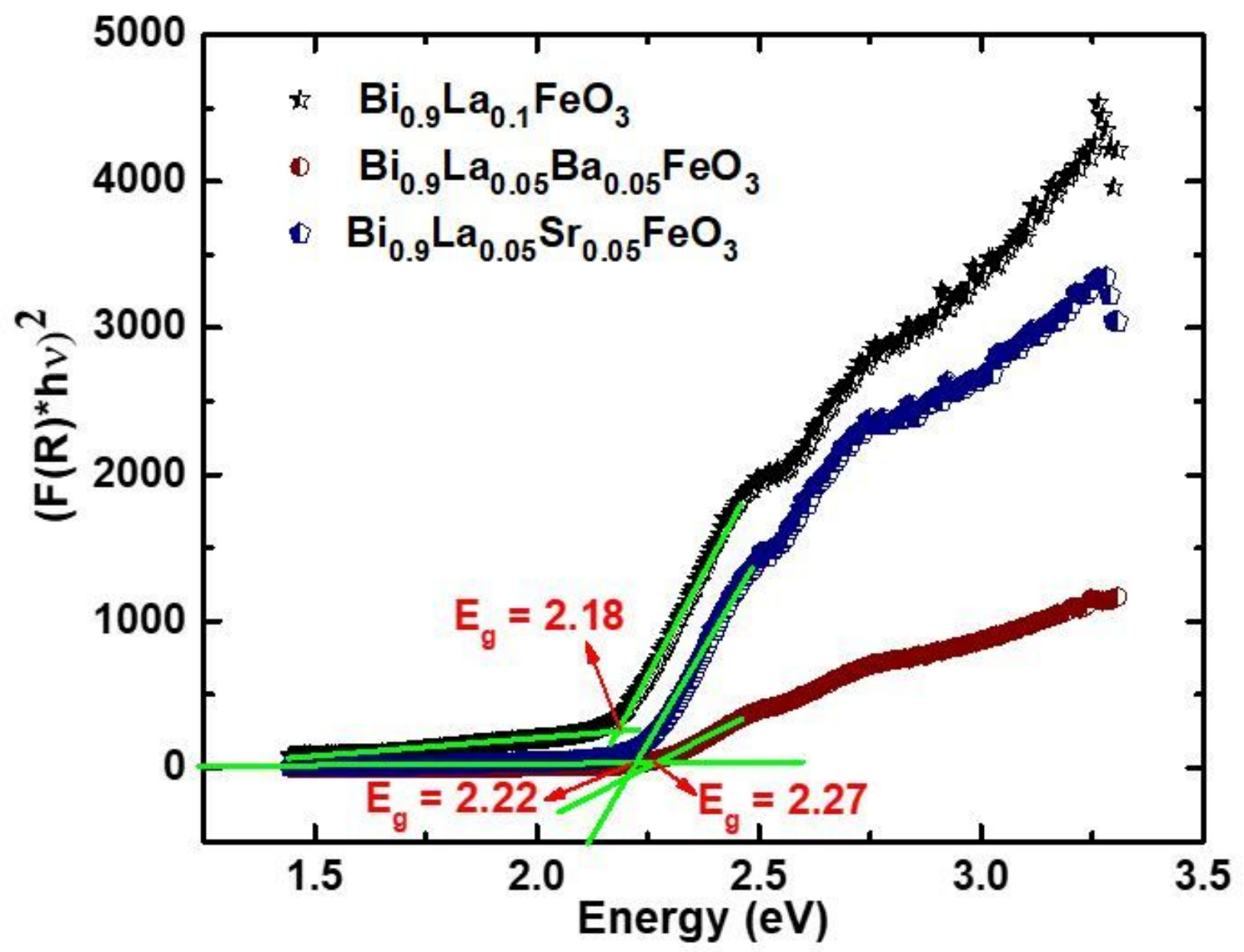

Figure 5

Tuac's plots for the estimation of optical bandgap of Bi0.9La0.1-x(Ba/Sr)xFeO3 $[x=0,0.05]$ ceramic materials 


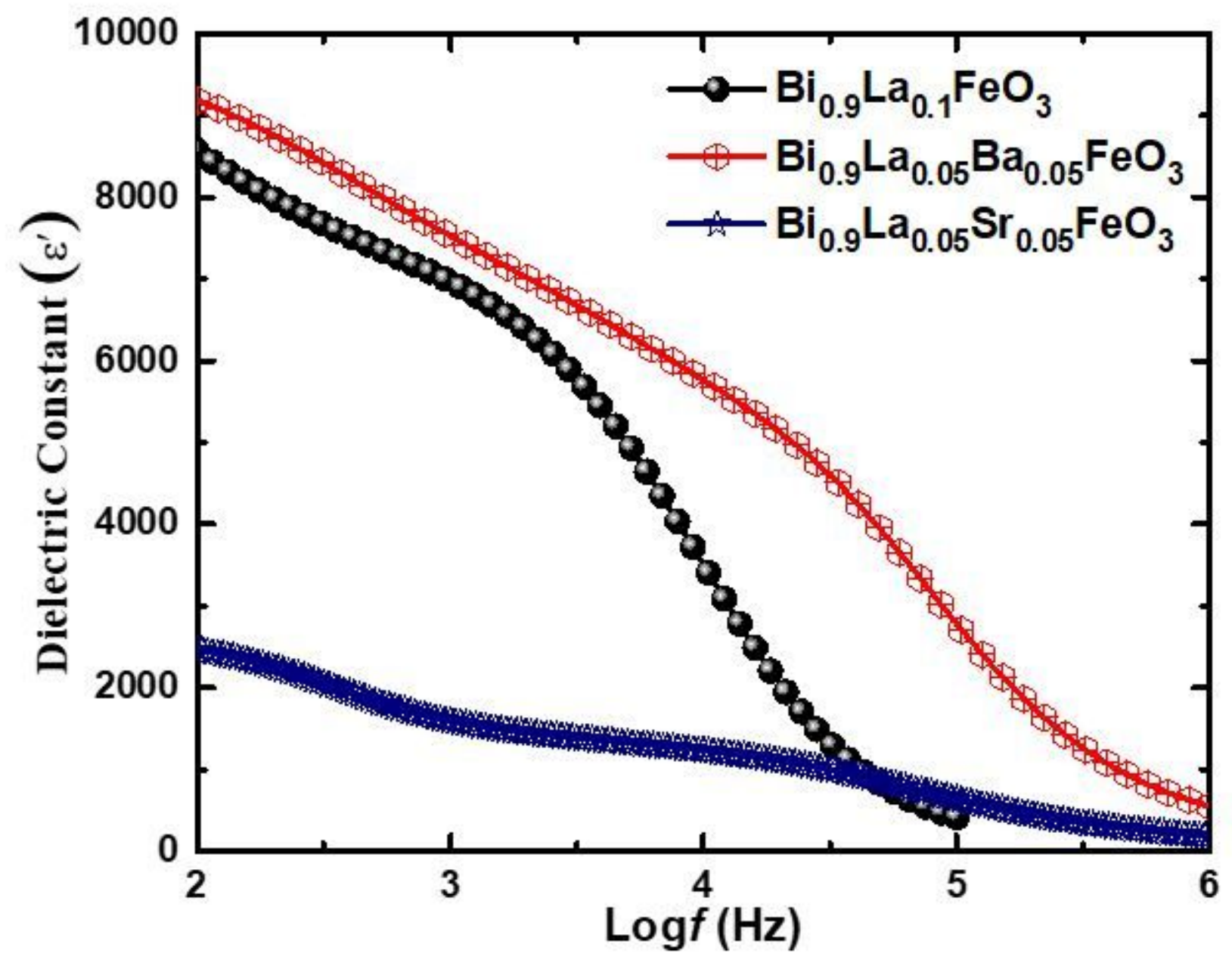

Figure 6

Dielectric constant of $\mathrm{Bi} 0.9 \mathrm{La} 0.1-\mathrm{x}(\mathrm{Ba} / \mathrm{Sr}) \mathrm{xFeO} 3[\mathrm{x}=0,0.05]$ ceramic materials 


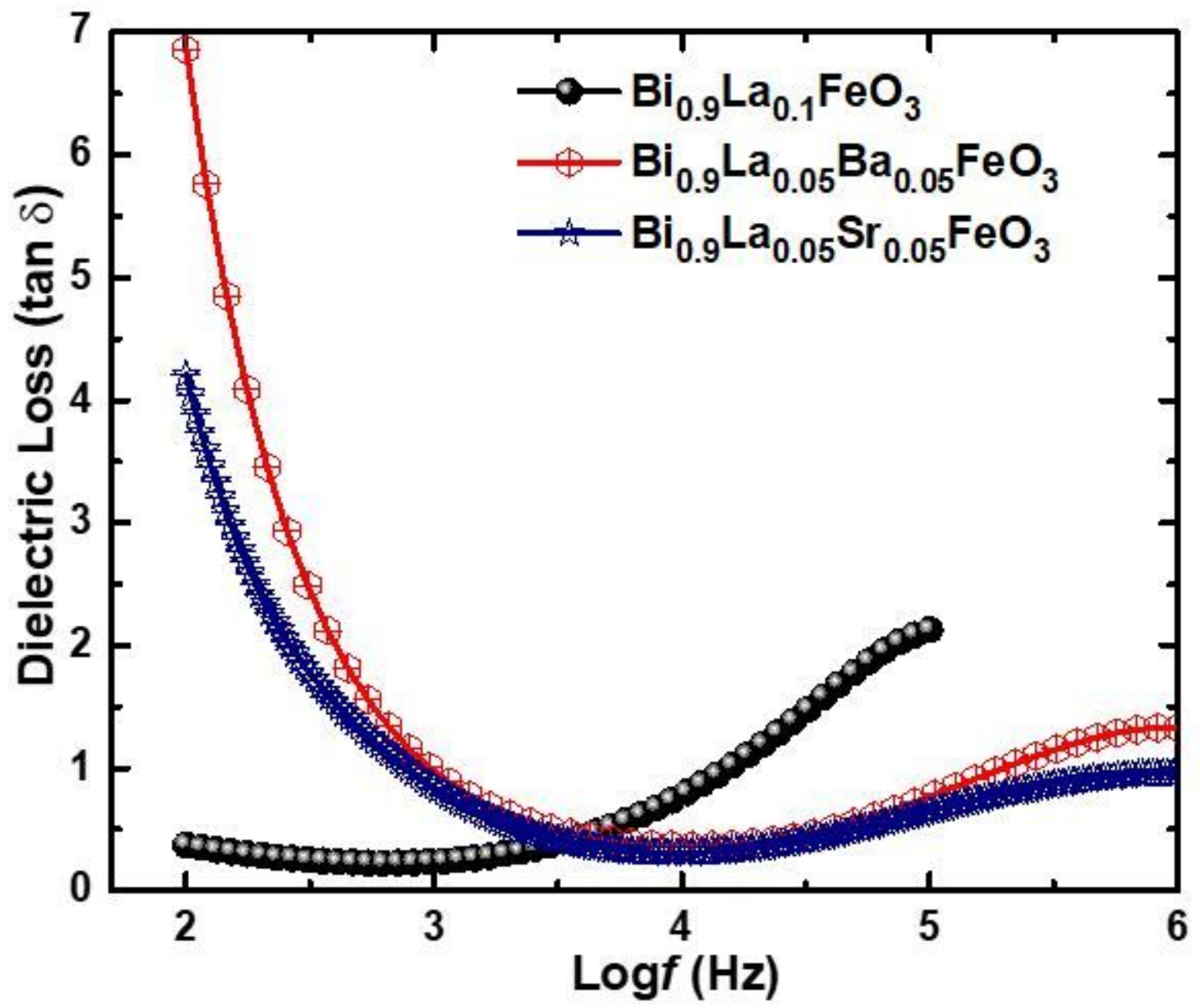

Figure 7

Dielectric loss $(\tan \delta)$ for Bi0.9La0.1-x $(\mathrm{Ba} / \mathrm{Sr}) \mathrm{xFeO}[\mathrm{x}=0,0.05]$ ceramic materials 


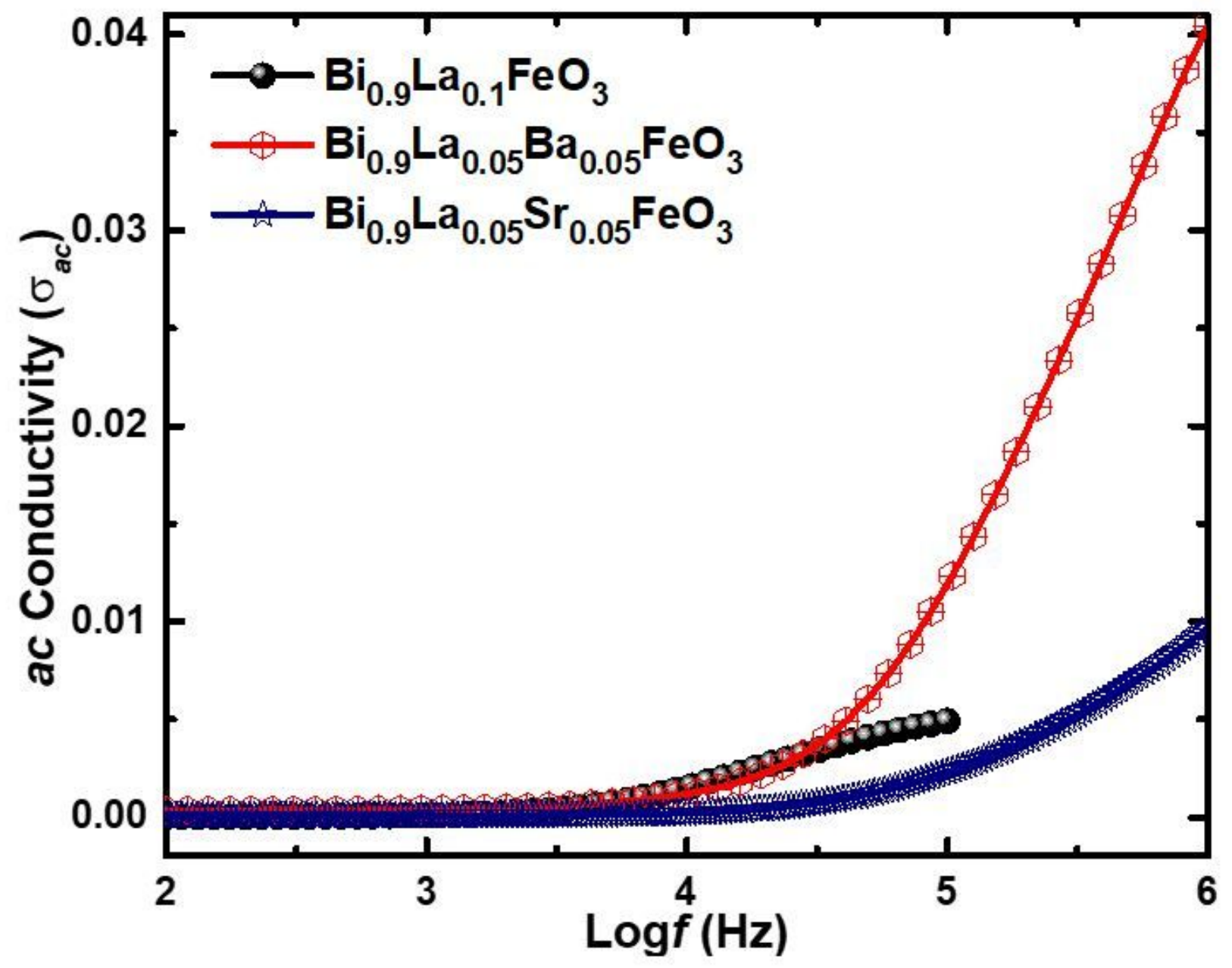

Figure 8

ac conductivity of $\mathrm{Bi} 0.9 \mathrm{La} 0.1-\mathrm{x}(\mathrm{Ba} / \mathrm{Sr}) \mathrm{xFeO} 3[\mathrm{x}=0,0.05]$ ceramic materials 


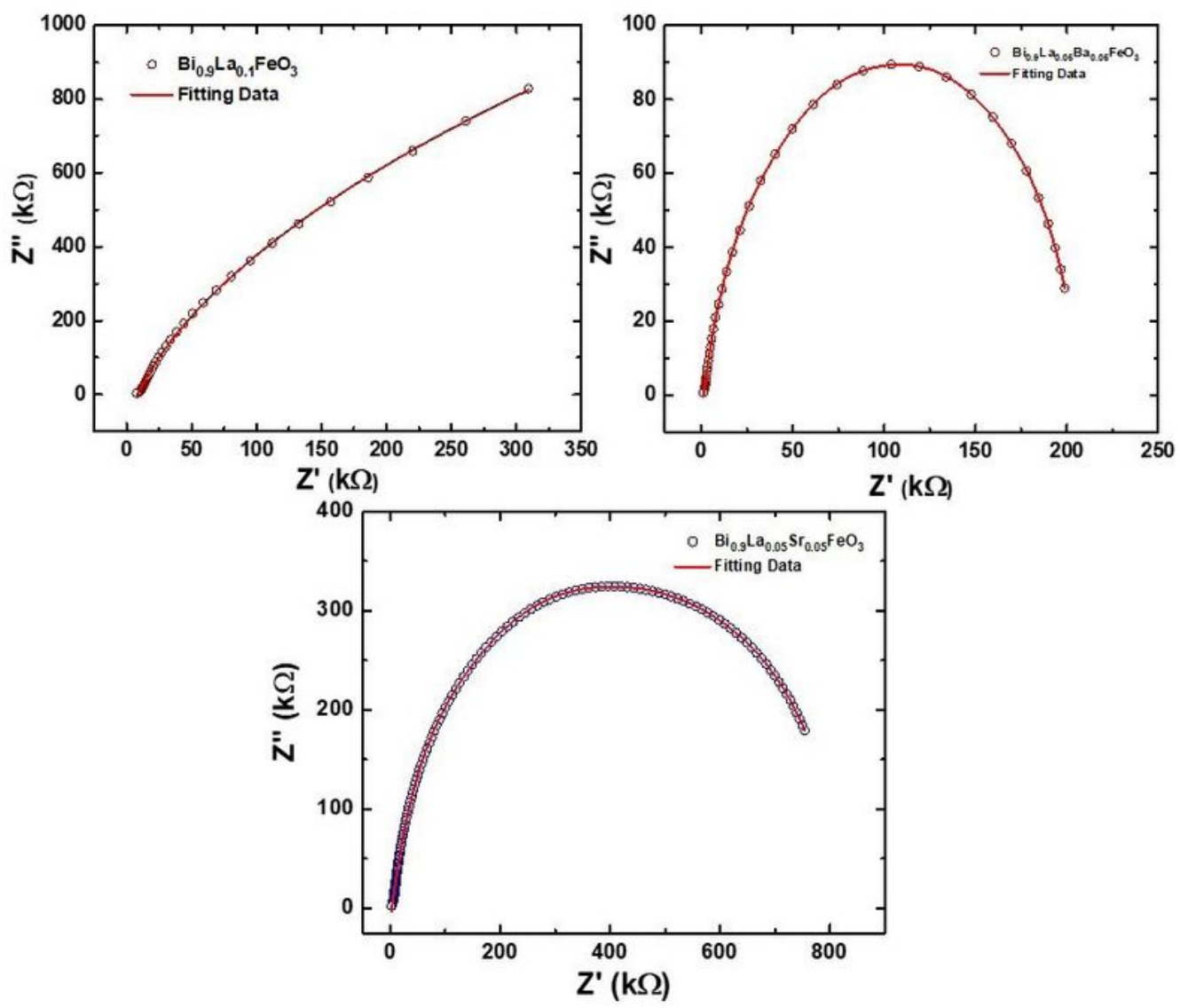

Figure 9 (a) and (b)
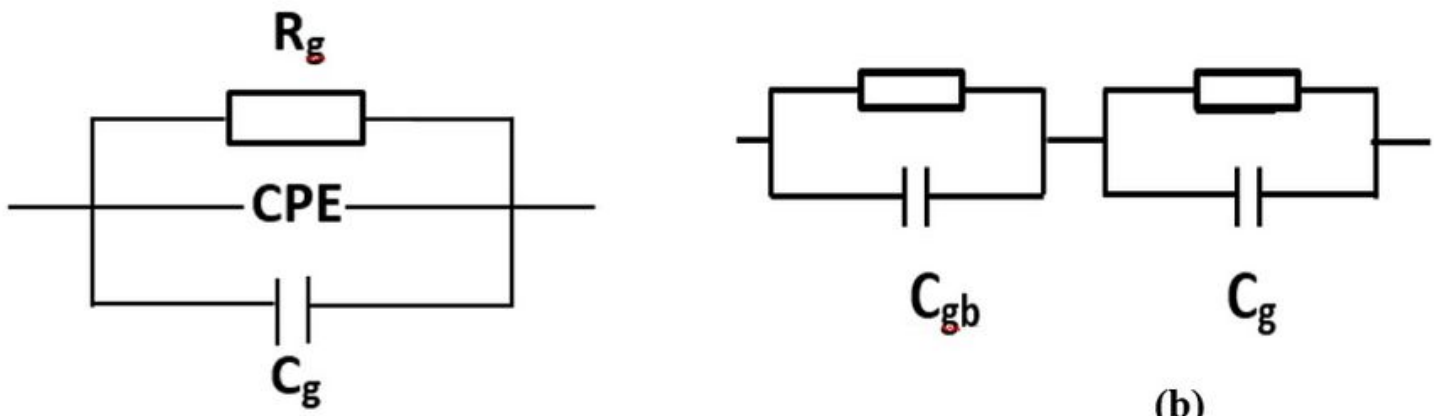

(a)

(b)

\section{Figure 9}

Nyquist plot of Bi0.9La0.1-x(Ba/Sr)xFeO3 $[x=0,0.05]$ ceramic materials (a) and (b): (a) ciruit for BLFO and (b) Circuit for BLBFO and BLSFO 


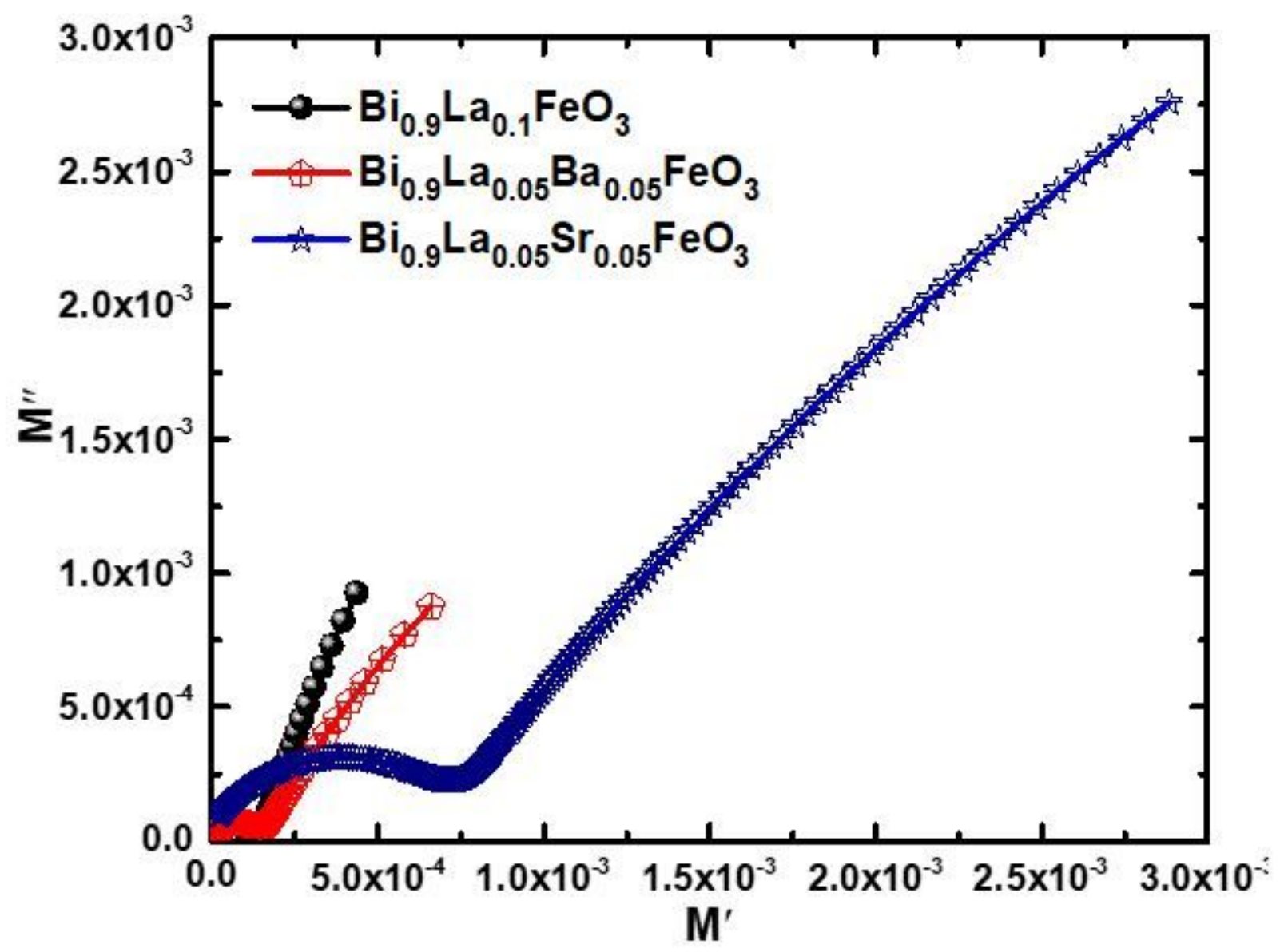

Figure 10

Cole-Cole plot for Bi0.9La0.1-x(Ba/Sr)xFeO3 $[x=0,0.05]$ ceramic materials 

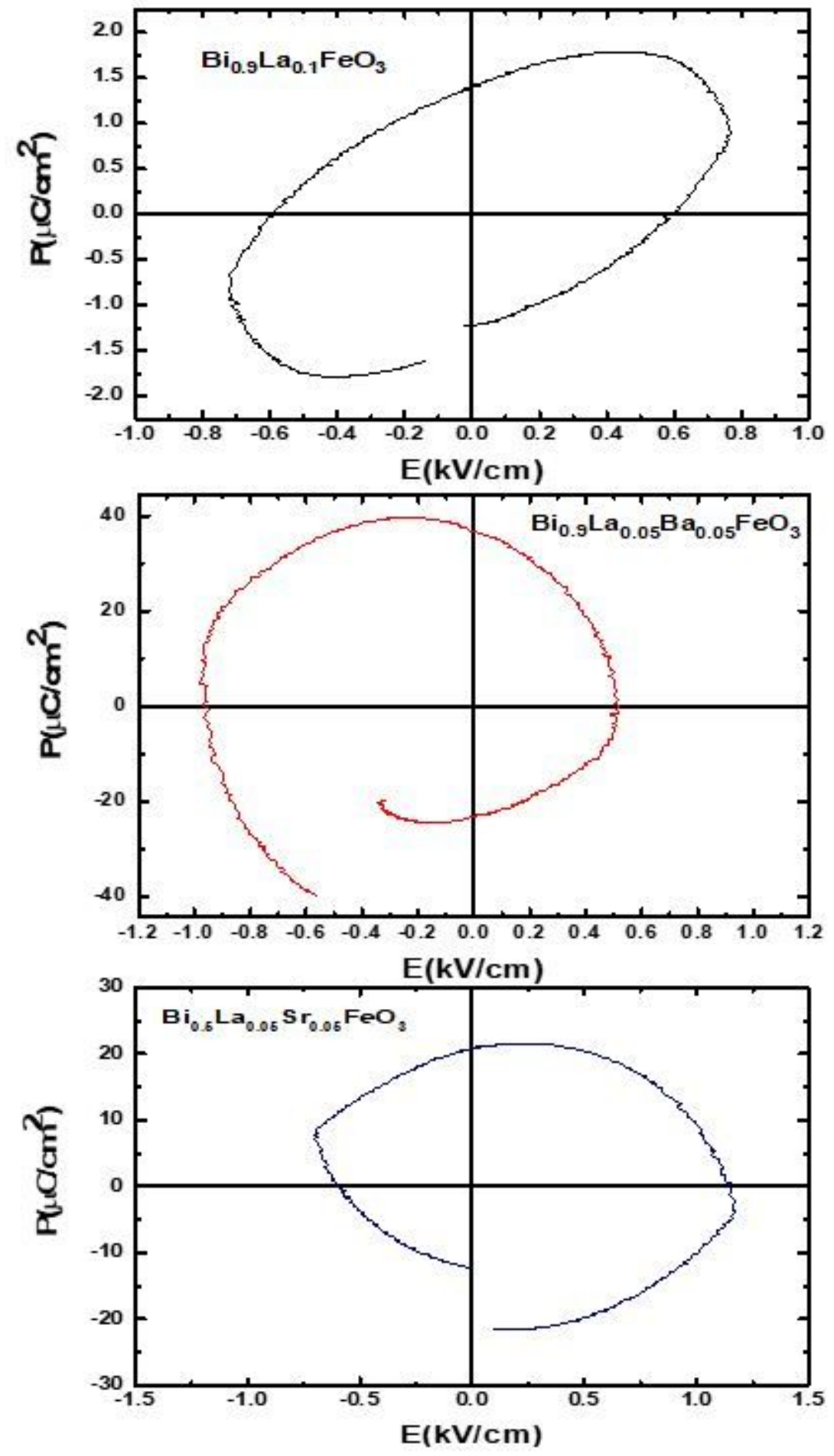

Figure 11

Polarization (P-E) loops of Bi0.9La0.1-x(Ba/Sr)xFeO3 $[x=0,0.05]$ ceramic materials 